\title{
20. THE PLANNING AND EXECUTION OF A HIGH-RESOLUTION PALEOCEANOGRAPHIC DRILLING LEG: A SUMMARY ${ }^{1}$
}

\author{
Shipboard Scientific Party ${ }^{2}$
}

\section{GOALS}

While public awareness of the critical role the ocean plays in problems of global change has been a relatively recent phenomenon, the paleoceanographic community has long been cognizant of this. Over the last $10 \mathrm{yr}$, paleoceanographers have directed much effort to documenting the nature of oceanographic change on time scales of a few thousands to a few tens of thousands of years-time scales much closer to the mixing and residence times of many important components of the ocean-climate system. Unfortunately, these efforts have been limited to a select number of high-quality standard piston cores and thus have focused on the last few glacial cycles. The fundamental goal of Leg 138 was to attempt to apply this high-resolution approach to paleoclimatic studies to the long time-series recoverable only with ocean drilling. In doing so, we hoped to greatly extend our understanding of the history of Cenozoic sedimentation, paleoceanography, and climate.

\section{OBJECTIVES}

As we stated in the "Introduction" chapter (this volume), our primary objective for the Leg 138 transects was to provide information about the response to global changes in climate during the Neogene. The evolution of Earth's climate during this interval was marked by a number of global and local events. During the early Neogene, open circulation between the tropical Pacific and Atlantic oceans was possible through the Panamanian seaway. During the Pliocene, significant increases in Northern Hemisphere glaciations occurred. Isotopic evidence shows that at $2.4 \mathrm{Ma}$, the first major advance of Northern Hemisphere glaciers occurred (Shackleton et al, 1984). This event in the Northern Hemisphere should have had profound effect on the symmetry of Earth's thermal gradient, which would be reflected in circulation patterns of the atmosphere (Flohn, 1981).

Specific paleoceanographic questions we wished to address included the following:

1. How did Pacific Ocean equatorial circulation evolve through the late Cenozoic as a response to increased global glaciation?

2. Are oceanographic changes hemispherically symmetrical or asymmetrical?

3. What was the nature of the circulation system during the late Miocene, when open communication with the Atlantic Ocean occurred through the Panamanian seaway?

4. What was the nature of oceanographic variability during the late Miocene and Pliocene and how does this compare with that of the Pleistocene (i.e., did changing boundary conditions modify the sensitivity of the system)?

5. What was the nature of circulation during the Pliocene after the closure of Panama, but before the onset of Pleistocene glaciation in the Northern Hemisphere?

6. How did oceanographic changes affect productivity in the equatorial Pacific Ocean surface waters?

${ }^{1}$ Mayer, L., Pisias, N., Janecek, T., et al., 1992. Proc. ODP, Init. Repts., 138: College Station, TX (Ocean Drilling Program).

${ }^{2}$ Shipboard Scientific Party is as given in list of participants preceding the contents.
7. How were paleoceanographic changes expressed in the physical, acoustic, and color properties of the sediment; can high-resolution seismic data be a useful paleoceanographic tool?

\section{PRELIMINARY RESULTS}

While many of these questions will be answered by post-cruise research, we defined two high priority objectives to be accomplished at sea:

1. Real-time monitoring of drilling to assure as complete a recovery of the sedimentary section at each site as possible and

2. The development of a high-resolution stratigraphic framework.

\section{Section Recovery}

Previous drilling programs showed that even when the sedimentary section was sampled using the hydraulic piston corer, significant amounts of the section were missed at the levels that fall between consecutive cores. To collect $100 \%$ of the sedimentary column, parallel holes must be cored with core breaks carefully offset. During Leg 138, a number of new strategies and data analysis procedures were incorporated to help assure complete section recovery. With these strategies, we demonstrated that in the overlapping APC-cored section at all but one site (Site 853), $100 \%$ of the sedimentary section could be recovered. Using similar strategies for the XCB-coring tool, we estimate that even with $100 \%$ core recovery, a sampled section having continuous $\mathrm{XCB}$ core will sample only about $75 \%$ of the total section.

To monitor the coring process, we used three types of continuously measured sedimentary properties: (1) sediment density (measured by the GRAPE system), (2) sediment magnetic susceptibility, and (3) multiwavelength sediment color reflectance. The first two features were measured using the ODP MST system, which measures sediment density and magnetic susceptibility in whole-core samples at intervals of 2 and $5 \mathrm{~cm}$, respectively. These measurements were performed as soon as the core reached the laboratory; data were immediately transferred to the shipboard computer system and made available to the scientific party.

Color reflectance of split sediment cores was measured using an automated tracking system developed at Oregon State University. This system measures the reflectance of light at 511 different wavelengths that range from the visible to the near-infrared. Measurements were performed usually at $3-\mathrm{cm}$ intervals over an area covered by a 2-cm-diameter spot. These data were collected using an IBM-PC compatible computer and then transferred to a SUN Sparc workstation and made available to shipboard sedimentologists before core description was completed.

These continuously measured data were used to monitor core recovery and to construct a composite section at each drill site. Figure 1 of Chapter 5 (Hagelberg et al., this volume) illustrates a section of GRAPE data from Site 849 . Each trace shows density that was measured in successive cores from different holes drilled at the site. Using computer software written especially for workstations installed during Leg 138, the cores from each hole could be aligned on the basis of correlation of each data series. During this correlation process, each core was shifted only in its relative position, with no stretching or 


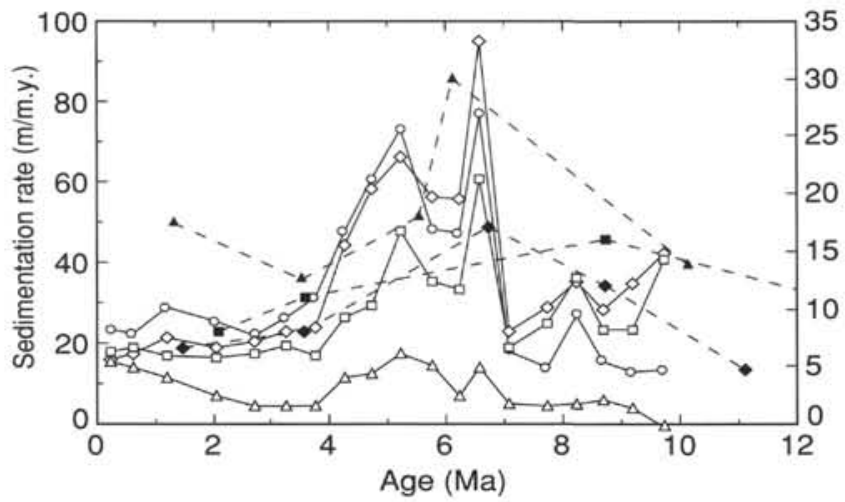

Figure 1. Sedimentation rates for sites along the $110^{\circ} \mathrm{W}$ transect. Site $806=$ closed squares; Site 851 = open squares; Site $573=$ closed triangles; Site 849 $=$ open circles; Site $848=$ open triangles; Site $850=$ open diamonds; and Site $707=$ closed diamonds.

compression of core lengths. The process of correlating cores among holes was completed using, when available, three independent data sets: GRAPE density, sediment magnetic susceptibility, and total color reflectance. After all cores were aligned in such a way as to satisfy all data sets, a composite section for each site could be generated so as to eliminate intercore gaps (see Hagelberg et al., this volume, for details). This technique was also used, in near real-time, to guide drilling so as to ensure proper overlapping of core.

Results of this process are shown in Figure 1 from Chapter 6 (this volume), where the composite GRAPE records are shown vs. composite depth in meters. As noted by scientists of previous legs of the Deep Sea Drilling Project and ODP, the splicing of parallel holes often results in a composite section that is longer than the section actually drilled (typically about $10 \%$ in the APC-cored interval). A small amount of stretching (at most $5 \%$ at these water and sediment depths) can be accounted for by sediment expansion from pressure changes, but the full extent of stretching remains unexplained.

The compositing performed at each site showed that for 10 of the Leg 138 sites, $100 \%$ of the sedimentary section was recovered when multiple holes were sampled with the APC-coring system. At Site 853, excessive ship's heave in seas set up by $30-\mathrm{kt}$ winds made it difficult to control the overlapping among the holes drilled at the site. The drilling of parallel holes at Sites 849 and 851 using the XCB-coring system suggests that about $75 \%$ of the section was recovered with a single XCB hole, even should $100 \%$ core recovery be recorded.

An independent test of core recovery and constructed composite sections was provided by the downhole logging program conducted during Leg 138. Figure 6 from Chapter 5 (this volume) shows a comparison of sediment density measured by borehole logs and the composite GRAPE record for five sites where downhole density logs were measured. In this figure, the depth scale of the composite GRAPE records was adjusted back to meters below seafloor. For this figure, conversion from the composite depth units was performed by plotting the composite depth of each core vs. its measured sub-bottom depth. In all cases, this plot could be described by one or two straight-line segments. While the density logs do not provide data in the shallowest part of the section, the match between the log-measured density and density directly measured in sediment samples is good and suggests that the compositing strategy works well.

\section{Stratigraphic Framework}

Critical to any paleoceanographic study is a stratigraphic framework. For high-resolution paleoceanographic studies, such as those envisioned for Leg 138, the demand on stratigraphy is even greater. If we are to study the response of the equatorial Pacific Ocean to changes in climate on time scales of a few to a few tens of thousands of years, then the stratigraphy must be of similar quality.

Initial stratigraphy for each Leg 138 site was developed using the excellent quality of marine microfossil records contained in the sediments of the equatorial Pacific Ocean. In general, all major fossil groups, calcareous nannofossils, diatoms, foraminifers, and radiolarians, were present. In addition, paleomagnetic results were also successful. The combined paleomagnetic records from Sites 844 and 845 in the northeastem part of the study area provided a complete record of polarity reversals from the Brunhes to Chron $5 \mathrm{AB}$. Excellent magnetic polarity sequences also were obtained from Sites $848,851,852,853$, and 854 . These results will greatly improve our ability to correlate biostratigraphic events with the magnetic polarity time scale.

Given the high-quality biostratigraphic and paleomagnetic data, a number of additional factors helped when developing a high-resolution stratigraphic framework. First, was the drilling/logging strategy used at each site. Unlike most previous legs, when all drilling and coring was completed before logging operations started, the first hole at each site was drilled to basement and then logged. This strategy provided the Shipboard Scientific Party time to complete our preliminary stratigraphy of the site, as well as allowed us to process the GRAPE, sediment magnetic susceptibility, and color reflectance data. This strategy also allowed us to compare laboratory records with downhole logs and thus to identify potential gaps in the core record. After logging, we began the next hole. Second, because the MST data were collected in real time, allowing us to construct a composite depth section as coring proceeded, a more directed micropaleontological sampling scheme could be developed for successive holes at each site. This allowed us to determine biostratigraphic events at much higher resolution than normally has been achieved aboard the ship.

And finally, the remarkable correlation between the sediment density records (which in this region reflect changes in concentration of calcium carbonate relative to opaline silica [Mayer, 1991]) allowed us to correlate more finely among sites than we could using magnetostratigraphy or biostratigraphy alone. The quality and resolution of this stratigraphic framework is illustrated in Figure 1, where sedimentation rates for the sites along the $110^{\circ} \mathrm{W}$ transect have been plotted vs. age. Also shown are the estimated sedimentation rates for sites drilled as part of DSDP Leg 85 and sites from ODP Legs 115 and 130. Results for Legs 85 and 115 are from published final volumes of these legs, while results from Leg 130 are from the Initial Reports volume of the leg. Clearly, the stratigraphy developed at sea during Leg 138 is of much higher resolution and will greatly aid our efforts to reconstruct the paleoceanography of the eastern equatorial Pacific Ocean.

\section{REFERENCES}

Flohn, H., 1981. A hemispheric circulation asymmetry during late Tertiary. Geol. Rundsch., 70:725-736.

Mayer, L. A., 1991. Extraction of high-resolution carbonate data for paleoclimate reconstruction. Nature, 352:148-151.

Shackleton, N. J., Backman, J., Zimmerman, H., Kent, D. V., Hall, M. A., Roberts, D. G., Schnitker, D., Baldauf, J., Desprairies, A., Homrighausen, R., Huddlestun, P., Keene, J. B., Kaltenback, A. J., Krumsiek, K.A.O., Morton, A. C., Murray, J. W., and Westberg-Smith, J., 1984. Oxygen isotope calibration of the onset of ice-rafting in DSDP Site 552A: history of glaciation in the North Atlantic region. Nature, 307:620-623. 